\title{
Análise das contingências presentes na orientação de pais na clínica analítico-comportamental infantil
}

\section{Analysis of the contingencies present in the parents' orientation in the child

\author{
behavioral analytic clinic
}

\author{
Cintia Figueiredo de Norões Brito*, Ana Rodrigues Costa** \\ *Universidade Fernando Pessoa, ** Universidade Fernando Pessoa
}

\begin{abstract}
Resumo
Buscando compreender a orientação de pais a partir de fatores descritos pela literatura como influentes no processo de generalização (Ocorrência de Orientação, Dinâmica familiar e Regras Funcionais), Os participantes foram 38 pais de crianças atendidas em consulta de Psicólogos com orientação Analitico-Comportamentais. No que se refere ao material, utilizou-se um inquérito por questionário, o Questionário de Compreensão do Processo de Orientação de Pais (Brito \& Costa, s/d). Os resultados constataram correlações positivas e significativas entre o processo de generalização e as categorias estudadas, indicando que o psicólogo precisa avaliar e intervir nestas variáveis para melhores efeitos terapeuticos.

Palavras-chave: terapia analítico-comportamental infantil; relação terapêutica; treino de habilidades sociais de pais; generalização.
\end{abstract}

\begin{abstract}
Aiming to understand parents' orientation from factors described by literature as influential in the generalization process (Occurrence of Guidance, Family Dynamics and Functional Rules), the participants were 38 parents of children attended in consultation with Analytical-Behavioral Psychologists, (Brito \& Costa, s / d) - The results showed positive and significant correlations between the process of generalization and the categories studied, Indicating that the psychologist needs to evaluate and intervene in these variables for better therapeutic effects.

Keywords: child behavioral analytic therapy; Therapeutic relationship; Parenting skills training; Generalization.
\end{abstract}

Diante das características da terapia analítico-comportamental infantil, destaca-se a participação de pais e cuidadores como assunto de estudo deste trabalho.

No que se referem às práticas educativas negativas (estabelecimento de limites e consequenciação de comportamentos inadequados), estas têm sido relacionadas com os problemas de comportamento infantis (Alvarenga \& Piccinini, 2001; Cecconelo, Antoni \& Koller, 2003; Oliveira, Marin, Pires, Frizzo,
Ravanello \& Rossato, 2002; Salvo, Silvares \& Toni, 2005).

Outra relação importante na teoria analítico-comportamental refere-se à definição de regras, que são estímulos discriminativos de um tipo especial, pois envolvem o comportamento verbal de uma pessoa, aquela que a emite (Matos, 2001). Portanto, o comportamento controlado por regras deve ser estudado envolvendo uma análise acerca do contexto social do emissor e do receptor da regra, cabendo a este segui-la ou não. As regras possuem o sentido de descrever as contingências sendo, portanto, condições especiais que podemos utilizar ao analisarmos o comportamento do sujeito, lembrando que são exemplos de comportamento verbal e, deste modo, gerados no ambiente em que vivemos (Matos, 2001).

O ambiente familiar pode ser responsável pela promoção/manutenção de comportamentos adequados ou inadequados (Bolsoni-Silva \& Maturano, 2002). As autoras afirmam que, além de fornecer informações aos pais sobre os métodos educativos mais efetivos e positivos, é necessário instrumentalizá-los no sentido de torná-los capazes de estabelecer os limites, evitando o uso da punição, atuando na prevenção/solução de problemas sem prejuízos para a relação com os filhos.

$\mathrm{O}$ objetivo da presente pesquisa consiste em compreender o processo orientação de pais a partir de relações de fatores descritos pela literatura como influentes no processo de generalização de ganhos terapêuticos, a saber: Ocorrência de Orientação, Dinâmica Familiar e Regras Funcionais.

\section{.Método}

Participantes. Os participantes são pais que estiveram aguardando seus filhos serem atendidos em consultórios por psicólogos com orientação teórica analítico-comportamental infantil na cidade de Fortaleza, Ceará, Brasil. Trata-se assim de uma amostra por conveniência (Hill \& Hill, 2000).

Os questionários foram respondidos por mães $(68,4 \%)$, pais $(23,7 \%)$, pai e mãe $(5,3 \%)$ e uma avó $(2,6 \%)$ de clientes atendidos na cidade de Fortaleza/CE. 
Estes se declararam casados $(68,4 \%)$, solteiros $(7,9 \%)$, em união estável $(2,6 \%)$, divorciados $(15,8 \%)$ ou viúvos $(5,3 \%)$. Quanto à escolaridade, a maioria, tanto dos pais $(65,8 \%)$, quanto das mães $(78,9 \%)$, indicou possuir ensino superior completo. As crianças atendidas distribuíram-se equitativamente em função do sexo e apresentaram idades entre 2 e 15 anos $(M=7,7 ; D P=$ $3,11) ; 52,6 \%$ têm pais que fizeram ou fazem terapia (individual ou familiar).

Materiais. Utilizou-se um inquérito por questionário, o Questionário de Compreensão do Processo de Orientação de Pais (Brito \& Costa, s/d) elaborado com base na literatura especializada na área. O questionário é constituído por 20 questões, sendo a última delas composta por 8 itens. Todas as perguntas são objetivas e as respostas dispostas em escala likert.

Os itens do questionário estão agrupados em categorias,procedimento esse que teve como embasamento a literatura estudada:

Generalização (Questões 6, 7, 8, 20a, 20b e 20c): envolve o processo de generalização como um todo. As questões inclusas nesta categoria são referentes às etapas do processo de generalização na situação de orientação de pais, por exemplo: saber se os pais estão lembrando-se de seguir as orientações em casa; compreendendo as orientações; tentando e conseguindo seguir as orientações. Esta categoria abrange as diferentes fases do processo de generalização em situação de orientação de pais.

Ocorrência da orientação (Questões 4 e 5): o objetivo desta categoria é identificar se a orientação de pais está acontecendo e, em caso afirmativo, com qual frequência. Em outras palavras, é necessário verificar se os psicólogos estão realizando a orientação parental e com quanto tempo de intervalo, levando-se em consideração a opinião dos pais.

Dinâmica familiar - Participação do cônjuge nos processos de orientação/generalização (Questões 13, 15,16 e 20d): categoria que envolve questões referentes à participação do cônjuge no processo de seguir as orientações fornecidas pela psicóloga e à participação do cônjuge no processo de orientação. As perguntas incluem o processo de orientação e generalização, desde buscar saber se o cônjuge está recebendo as orientações, até saber se ele está entendendo ou seguindo as mesmas.

Regras Funcionais (Questões 17 e 18): esta categoria envolve a identificação de regras ou auto-regras funcionais dos pais em relação ao processo terapêutico dos seus filhos. É necessário identificar as regras adaptativas presentes no tratamento terapêutico das crianças, visto que elas podem influenciar no seguimento, ou não seguimento, das orientações fornecidas pelo psicólogo, como discutido nos capítulos teóricos. Os itens verificados nesta categoria abrangem perguntas como saber se os pais acreditam que seguir as orientações pode ajudar no comportamento de seus filhos ou saber se eles acham importante segui-las.

Procedimento. Com o estudo da referência bibliográfica, foi elaborado pela pesquisadora e pela orientadora, o questionário que serviu de instrumento para investigar as relações de contingências envolvidas no processo de generalização de ganhos terapêuticos em situação de orientação de pais na clínica analítico-comportamental infantil, como descrito no item anterior (Materiais).

Foi elaborado um projeto de pesquisa que foi submetido à Comissão de Ética da Universidade Fernando Pessoa. Com o recebimento do documento de aceitação deste, iniciamos a execução do estudo. Selecionamos quatro alunos de Psicologia da Universidade Federal do Ceará por meio de entrevistas que foram treinados para a aplicação dos questionários. Solicitamos a psicólogos analítico-comportamentais de Fortaleza (8) após explicarmos os procedimentos, objetivos e documentos do estudo, solicitando a permissão para aplicação dos questionários.

Os alunos de psicologia iniciaram a aplicação individual dos questionários aos pais de pacientes que estavam aguardando, na sala de espera, seus filhos serem atendidos por psicólogos analítico-comportamentais. Esta fase envolveu a apresentação de uma folha de rosto contendo informações sobre a pesquisa e o consentimento informado para assinatura dos participantes antes de responder o questionário. Após a assinatura do mesmo e dos esclarecimentos considerados necessários, era entregue o questionário que, depois de respondido, deveria ser depositado em uma urna para garantir o caráter anônimo do procedimento.

Depois de recolhidos, os dados estes foram trabalhados recorrendo ao Statistical Package for the Social Sciences (SPSS).

\section{Resultados}

Antes de efetuar as correlações entre as categorias utilizadas no presente estudo, buscou-se atestar a confiabilidade das perguntas do questionário, avaliando se os itens construídos apresentavam consistência interna satisfatória. Para tanto, foi calculado o Alfa de Cronbach, considerando o agrupamento dos itens. O resultado dessa análise revelou um alfa de 0,71 , que, segundo a literatura, pode ser compreendido como satisfatório (Nunnally, 1978).

Os dados coletados foram analisados a partir do SPSS (Versão 22). Além das estatísticas descritivas (Tendência Central e Dispersão), realizaram-se análises de correlação (Spearman) a fim de observar as relações entre as categorias estabelecidas.

Tabela 1

Correlação entre Generalização, Ocorrência de Orientação, Dinâmica Familiar e Regras Funcionais $(n=38)$.

\begin{tabular}{lc}
\hline Categorias & Generalizaç \\
& ão \\
\hline Ocorrência da & $0,41^{*}$ \\
Orientação & $0,41^{*}$ \\
Dinâmica Familiar & $0,43^{* *}$ \\
Regras Funcionais. \\
\hline Nota: ${ }^{*} p<0,05 ; * p<0,01$.
\end{tabular}

Como se observa, a Generalização está positivamente correlacionada com a Ocorrência da Orientação, com a Dinâmica familiar (Participação do cônjuge no processo 
de orientação/generalização) e com as Regras funcionais.

\section{Discussão}

A realização da presente pesquisa permitiu atingir os objetivos aos quais se propôs e elaborar conclusões sobre a compreensão do processo orientação de pais a partir de relações de fatores descritos pela literatura como influentes no processo de generalização de ganhos terapêuticos, a saber: Ocorrência de Orientação, Dinâmica Familiar (Participação do cônjuge/pai, no processo de orientação) e Regras Funcionais.

No que tange à relação entre as categorias Ocorrência da orientação e Generalização, os resultados demonstraram uma correlação significativamente positiva indicando que, na medida em que se amplia a frequência das orientações, se constata um aumento do processo de generalização (pais seguirem as orientações de pais). Estes resultados são semelhante encontrados por Bolsoni-Silva (2007) que, ao realizar uma revisão bibiográfica com estudos que avaliaram a efetividade das intervenções com pais para lidar com os comportamentos problemas dos filhos, identificou que houve resultados satisfatórios, como: aumento das práticas parentais positivas; redução das práticas parentais negativas; redução de problemas de comportamento. Estes resultados apontam no sentido de que o(a) psicólogo(a) deve considerar a orientação de pais como uma intervenção frequente na terapia infantil.

A Generalização também se correlaciona significativa e positivamente com a Dinâmica familiar (Participação do cônjuge na orientação/generalização). Como uma parte maioritária dos questionários foram preenchidos por mães, entende-se que a maioria das questões sobre a participação do cônjuge, dizem respeito aos pais. Então, assim, pode-se compreender que o aumento da participação dos pais nos procedimentos de orientação/generalização está relacionado com o aumento do processo de Generalização.

Borsa e Nunes (2008) realizaram um estudo sobre grau de concordância parental em relação aos problemas de comportamento infantil, utilizando o CBCL (Child Behavior Checklist) com instrumento. Os resultados obtidos apontam para um grau de concordância baixo a moderado, ou seja, pais e mães tendem a não concordar quando questionados sobre os comportamentos dos filhos.

Os resultados de Bolsoni-Silva et al. (2010) concluem que o trabalho combinado com pais e filhos pode propiciar melhores resultados. Estes dados estão de acordo com os encontrados na presente pesquisa, pois o processo de generalização demonstra maior frequência relacionada ao aumento da inclusão dos pais nos procedimentos de orientação/generalização. Os dados apontam para melhores resultados na generalização dos ganhos quando os pais estão envolvidos do processo terapêutico, demonstrando a importância do psicólogo garantir a inclusão de ambos nas orientações. Os planos de intervenção são, em geral, voltados para mães, sendo incomum a apresentação de programas que incluam os pais ou que sejam voltados para eles (Cia, Barham, \&
Fontaine, 2010; Fabiano, 2007; Fagan \& Iglesias, 1999; Lamb, 1997; Taylor \& Daniel, 2000). Outra questão observada refere-se à entrada da mulher no mercado de trabalho, observando-se, cada vez mais, a participação ativa de pais no cuidado com os filhos, seja na educação acadêmica, práticas de higiene, esportes, vida social ou estabelecimento de limites (Brandth \& Kvande, 2002; Cia \& Barham, 2008; Matta \& Knudson-Martin, 2006; Tiedje, 2004).

Verificou-se uma correlação significativamente positiva entre o processo de Generalização e as Regras/auto-regras Funcionais dos pais. Os resultados apontaram para uma relação em que o aumento das regras adaptativas, como acreditar que as orientações são importantes e que podem influenciar no tratamento do filho, constata uma maior frequência do processo de generalização.

Estas observações estão de acordo com a teoria analítico-comportamental que entende as regras como estímulos discriminativos especiais que descrevem uma contingência e que envolvem o comportamento verbal de uma pessoa, aquela que emite a regra (Matos, 2001). Em 1953, Skinner afirma que as regras são especialmente importantes quando as consequências naturais são falhas ou em longo prazo. As regras descrevem contingencias, ou seja, relações entre respostas e consequências, como: "Se você seguir as orientações da psicóloga terá bons resultados".

Esta reflexão é particularmente importante porque, além de fornecer as orientações, os psicólogos não têm dado muita atenção para verificar se as regras estão funcionando como estímulo discriminativo para o comportamento de seguir estas instruções. A correlação identificada neste tópico aponta para uma relação diretamente proporcional entre a existência de regras funcionais e a ocorrência da generalização. Desta forma, para garantir melhores resultados na prática clínica, em especial para a generalização, é necessário desenvolver técnicas que envolvam a avaliação e intervenção nas regras/auto-regras dos pais.

Como limitações do estudo, destaca-se o número reduzido de participantes e o facto de ser uma amostra de conveniência, o que impede a generalização dos resultados. Também o uso de um instrumento baseado no relato verbal, com toda a desejabilidade social que isso implica, sem associação com a observação direta ou com a recolha de dados junto dos psicólogos.

Apesar das limitações, deve-se ter em conta que, mesmo com uma amostra considerada pequena $(n=38)$, foi possível constatar correlações significativas e positivas entre as variáveis estudadas.

Mais do que responder perguntas, a grande contribuição deste trabalho é o questionamento acerca do processo de orientação de pais. Acredita-se que as inquietações com as dificuldades que são encontradas na prática clínica podem ser responsáveis pelo movimento de pesquisa e de constante produção de conhecimento. As respostas não devem funcionar como ponto de estagnação do estudo científico, e sim como um ponto de partida para outras perguntas, contribuindo para o enriquecimento científico. 


\section{Referências}

Alvarenga, P., \& Piccinini, C. (2001). Práticas educativas maternas e problemas de comportamento em pré-escolares. Psicologia: Reflexão e Crítica, 14, 449-460.

Brandth, B., \& Kvande, E. (2002). Reflexive fathers: Negotiating parental leave and working life. Gender, Work \& Organization, 9(2), 186-203.

Bolsoni-Silva, A. T. (2007). Intervenção em grupo para pais: descrição de procedimento. Temas em psicologia, 15(2), 217-235.

Bolsoni-Silva, A. T., \& Marturano, E. M. (2002). Práticas educativas e problemas de comportamento: uma análise à luz das habilidades sociais. Estudos de psicologia, 7(2), 227-235.

Bolsoni-Silva, A. T., Villas Boas, A. C. V. B., Leme, V. B. R., \& Silveira, F. F. (2010). Caracterização de programas de intervenção com crianças e/ou adolescentes. Arquivos brasileiros de psicologia, 62(1), 104-115.

Borsa, J. C., \& Nunes, M. L. T. (2008). Concordância parental sobre problemas de comportamento infantil através do CBCL. Paidéia, 18(40), 317-330.

Cecconello, A. M., De Antoni, C., \& Koller, S. H. (2003). Práticas educativas, estilos parentais e abuso físico no contexto familiar. Psicologia em Estudo, 8 (No. Esp.), 45-54.

Cia, F., \& Barham, E. J. (2008). Trabalho noturno e o novo papel: Uma interface difícil. Estudos de Psicologia (Campinas), 25(2), 213-233

Cia, F., Barham, E. J., \& Fontaine, A. M. G. V. (2010). Impactos de uma intervenção com pais: $O$ desempenho acadêmico e comportamento das crianças na escola. Psicologia: Reflexão e Crítica, 23(3), 187-197.

Fabiano, G. A. (2007). Father participation in behavioral parent training for ADHP: Review and recommendations for increasing inclusion and engagement. Journal of Family Psychology, 21(4), 683-693.

Fagan, J., \& Iglesias, A. (1999). Father involvement program effects on fathers, father figures, and their Head Start children: A quasi-experimental study. Early Childhood Research Quarterly, 14(2), 243-269.

Hill, M.M. \& Hill, A. (2000). Investigação por Questionário.Lisboa: Edições Sílabo.

Lamb, M. E. (1997). Fathers and child development: An introductory overview and guide. In M. E. Lamb (Ed.), The role of the father in child developmental, 3(1), (pp. 1-18). New York: John Wiley \& Sons.

Matta, D. S., \& Knudson-Martin, C. (2006). Father responsivity: Couple processes and the coconstruction of fatherhood. Family Process, 45(1), 19-37.

Matos, M. A. (2001). Comportamento governado por regras. Revista brasileira de terapia comportamental e cognitiva, 3(2), 51-66.

Nunnally, J. C. (1978). Psychometric theory. New York: McGraw-Hill.

Oliveira, E. D., Marin, A. H., Pires, F. B., Frizzo, G. B., Ravanello, T., \& Rossato, C. (2002). Estilos parentais autoritário e democrático-recíproco intergeracionais, conflito conjugal e comportamentos de externalização e internalização. Psicologia: reflexão e crítica, 15(1), $1-11$.

Salvo, C. G., Silvares, E. F. M., \& Toni, P. M. (2005). Práticas educativas como forma de predição de problemas de comportamento e competência social. Estudos de Psicologia (Campinas), 22, 187-195.

Skinner, B. F. (1993). Ciência e comportamento humano. Martins Fontes. $8^{\mathrm{a}}$ edição (Originalmente publicado em 1953).

Taylor, J., \& Daniel, B. (2000). The rhetoric versus the reality in child care and protection ideology and practice, in working with fathers. Journal of Advanced Nursing, 31(1), 12-19.

Tiedje, L. B. (2004). Processes of change in work/home incompatibilities: Employed mothers 19861999. Journal of Social Issues, 60(4), 787-800. 